\title{
Giant pseudoaneurysm of basilic vein complicating arteriovenous fistula
}

\author{
Ertan Demirdaş ${ }^{1}, K_{\text {Kvanç Atılgan}{ }^{1} \text {, Utkan Sevuk }}{ }^{1}$, Ferit Çiçekçioğlu ${ }^{1}$
}

1) Bozok University Research and Application Hospital and Cardiovascular Surgery, Yozgat, Turkey

\begin{abstract}
Arteriovenous fistulae are created for haemodialysis in patients with end-stage renal failure. Due to repeated punctures and concomitant heparinization an iatrogenic pseudoaneurysm is not a rare complication of patients having AVF. A case of a 58-year old patient having a pseudoaneurysm related to his sidetoside brachiobasilic AVF at the left antecubital region is reported in this article.
\end{abstract}

Keywords: Arteriovenous fistula, pseudoaneurysm, haemodialysis, renal failure

Arteriovenous fistulae (AVF) are created for haemodialysis in patients with end-stage renal failure. One of the complications of AVFs is iatrogenic pseudoaneurysms related to repeated punctures and concomitant heparinization. The incidence of pseudoaneurysms complicating AVF ranges from $2 \%$ to $10 \%{ }^{[1]}$

A 58-year old diabetic, hypertensive patient who had a sidetoside brachiobasilic AVF at the left antecubital region was referred to our clinic with a 4 months history of pulsatile swelling in his left arm (Figure 1).

He had been on hemodialysis for 4 years. Color Doppler Ultrasonography revealed a dysfunctioning fistula created between right brachial artery and basilic vein and a $62 \times 55 \mathrm{~mm}$ pseudoaneurysm of the left basilic vein. Moreover, venous thrombosis in the proximal portion of the left basilic vein was observed by color Doppler Ultrasonography. The patient underwent surgical repair. Pseudoaneurysm and the AVF was resected, and the defect on the arterial wall was primarily repaired (Figure 2, 3). Postoperative recovery was uneventful.

Development of pseudoaneurysm carries a high risk of AVF failure, thrombosis, infection, and hemorrhage. Treatment options include compression under ultrasonographic guidance, thrombin injection, endovascular cov- 


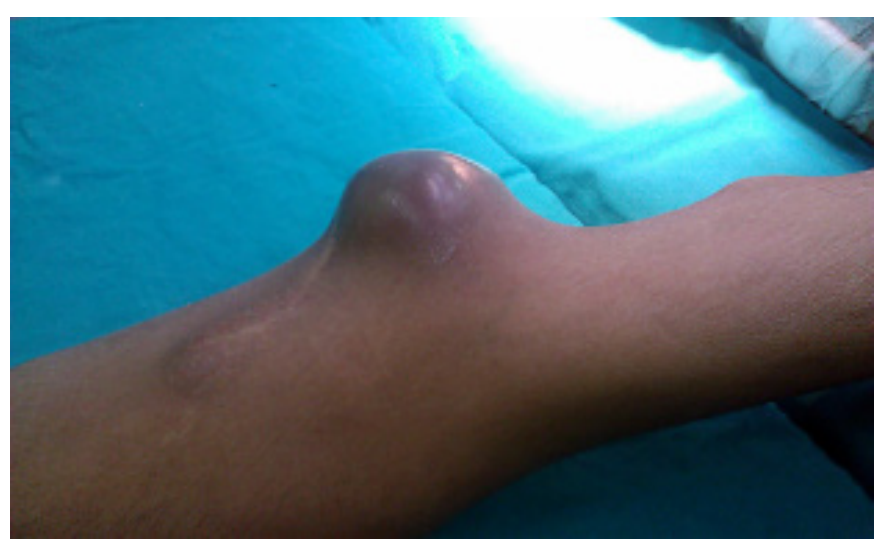

Figure 1.

ered stent implantation and surgical reconstruction.

Autologous AV fistulas have been shown to have superior long-term patency, lower incidence of complications and longer patient survival compared to arterio-

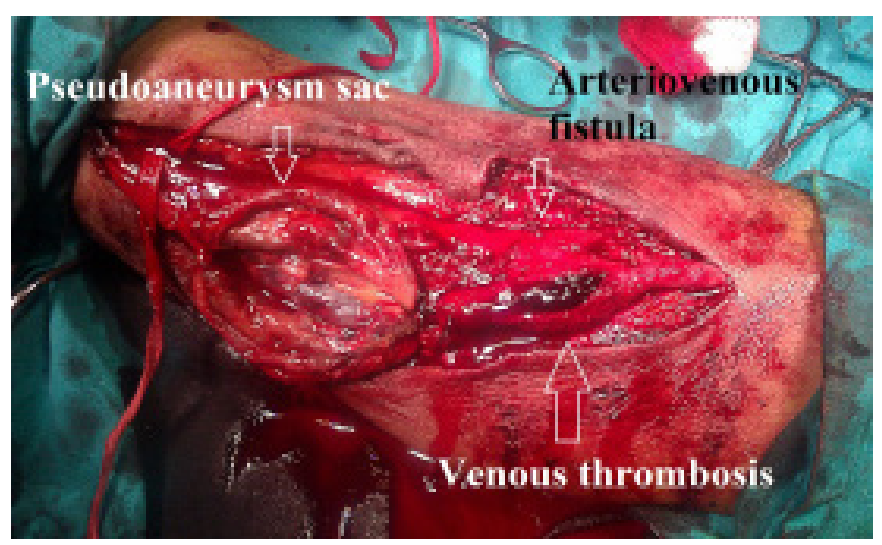

Figure 3.

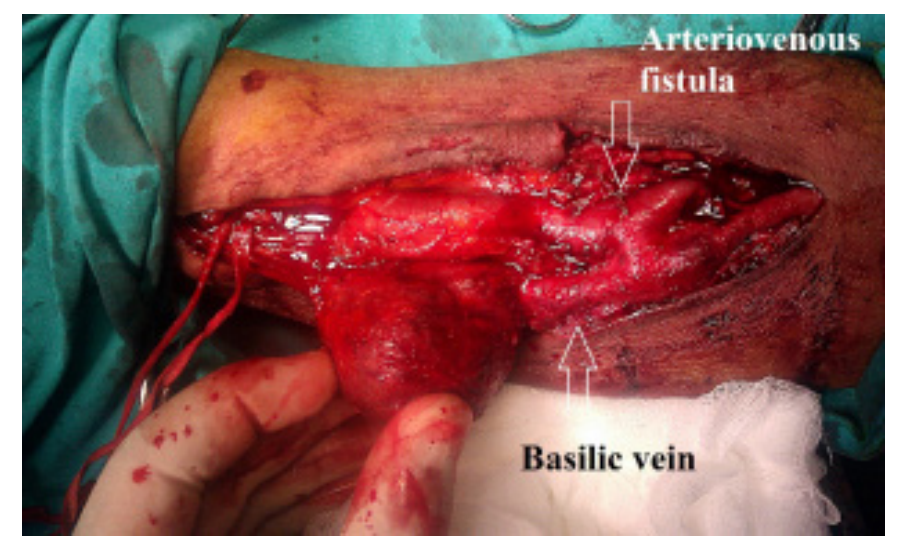

Figure 2.

venous grafts or central venous catheters. Thus, preservation of the arteriovenous fistula is critical to improved survival. Early diagnosis and prompt management of pseudoaneurysms are necessary to avoid AVF failure. ${ }^{[2,3]}$

\section{References}

1. Ballard JL, Bunt TJ, Malone JM. Major complications of angioaccess surgery. Am J Surg. 1992;164(3):229-32

2. Belli S, Parlakgumus A, Colakoglu T, Ezer A, Yildirim S, Moray G, Haberal M. Surgical treatment modalities for complicated aneurysms and pseudoaneurysms of arteriovenous fistulas. J Vasc Access. 2012;13(4):438-45

3. 3. Witz M, Werner M, Bernheim J, Shnaker A, Lehmann J, Korzets, Ultrasound-guided compression repair of pseudoaneurysms complicating a forearm dialysis arteriovenousfistula. Nephrol Dial Transplant. 2000;15(9):1453-4

Received: 10/08/2016

Accepted: 01/01/2017

Published: 15/03/2017

\section{Disclosure and conflicts of interest:}

Conflicts of interest were not reported.

\section{Corresponding author:}

Dr. Kıvanç Atılgan

Mail: kivancatilgan@gmail.com 